\title{
OBJECT ORIENTED CLASSIFICATION OF HIGH RESOLUTION DATA FOR INVENTORY OF HORTICULTURAL CROPS
}

\author{
R. Hebbar ${ }^{\mathrm{a}}$, H. M. Ravishankar ${ }^{\mathrm{a}}$, Shivam Trivedi ${ }^{\mathrm{a}}$, S.R. Subramoniam ${ }^{\mathrm{a}}$, Uday Raj ${ }^{\mathrm{a}}$ and V.K. Dadhwal ${ }^{\mathrm{b}}$ \\ ${ }^{a}$ Regional Remote Sensing Centre, NRSC/ISRO, ISITE campus, Marathahalli, Bengaluru, India- 560037 \\ hebbar_kr@nrsc.gov.in, (raviisro, shivam.trivedi, ramasubramoniams, udayraj.isro)@gmail.com \\ ${ }^{b}$ National Remote Sensing Centre, ISRO, Balanagar, Hyderabad, India- 500037 - (director@nrsc.gov.in)
}

\section{Technical Commission VIII}

Keywords: Horticultural plantations, high resolution data, texture, object oriented, classification accuracy, semi-automatic

\begin{abstract}
:
High resolution satellite images are associated with large variance and thus, per pixel classifiers often result in poor accuracy especially in delineation of horticultural crops. In this context, object oriented techniques are powerful and promising methods for classification. In the present study, a semi-automatic object oriented feature extraction model has been used for delineation of horticultural fruit and plantation crops using Erdas Objective Imagine. Multi-resolution data from Resourcesat LISS-IV and Cartosat-1 have been used as source data in the feature extraction model. Spectral and textural information along with NDVI were used as inputs for generation of Spectral Feature Probability (SFP) layers using sample training pixels. The SFP layers were then converted into raster objects using threshold and clump function resulting in pixel probability layer. A set of raster and vector operators was employed in the subsequent steps for generating thematic layer in the vector format. This semi-automatic feature extraction model was employed for classification of major fruit and plantations crops viz., mango, banana, citrus, coffee and coconut grown under different agro-climatic conditions. In general, the classification accuracy of about 75-80 per cent was achieved for these crops using object based classification alone and the same was further improved using minimal visual editing of misclassified areas. A comparison of on-screen visual interpretation with object oriented approach showed good agreement. It was observed that old and mature plantations were classified more accurately while young and recently planted ones (3years or less) showed poor classification accuracy due to mixed spectral signature, wider spacing and poor stands of plantations. The results indicated the potential use of object oriented approach for classification of high resolution data for delineation of horticultural fruit and plantation crops. The present methodology is applicable at local levels and future development is focused on up-scaling the methodology for generation of fruit and plantation crop maps at regional and national level which is important for creation of database for overall horticultural crop development.
\end{abstract}

\subsection{INTRODUCTION}

The horticultural scenario of the country has been changing fast both in terms of production and productivity. India is the second largest producer of fruits and vegetables in the world and is the leader in several horticultural crops like mango, banana, papaya, cashewnut, arecanut, potato, etc. The total horticultural production in the country touched 240 MT in 2010-11 (IHD, 2013). Horticultural crops occupy about 17.6 per cent of net sown area in India. In view of the commercial and economic importance of horticultural crops, it is imperative to have proper planning for enhancing the productivity (NHRDF, 2012). The basic requirements for proper planning of these crops are the availability of reliable statistics in terms of area and production at different spatial hierarchies (tehsil, district and state). Hence, availability of reliable statistical database at micro level is one of the most critical requirements for efficient policy planning for proper development and management of resources.

Medium resolution satellite data is being operationally used for mapping and monitoring of agricultural crops (Dadhwal et al., 2003, Tenkabail et al., 2004, Murthy et al., 2007). However, systematic studies for exploring the utility of RS data for inventory of horticultural fruit and plantation crops are limited. Recently, pilot studies have successfully demonstrated the potential use of high resolution Cartosat-1 and LISS-IV data for discrimination and mapping of major plantation crops like rubber, tea and coffee. The conventional per pixel classifiers have limited application for classification of horticultural crops to achieve reasonable accuracy due to large spatial heterogeneity (Hebbar and Rao, 2002, Yadav et al., 2002; Srivastava and Gebelein, 2007). Hence, Visual interpretation techniques have been adopted for mapping of plantation crops (RRSC-South, 2012).

Advanced object based classifiers have shown promising results for classification of high resolution data for mapping of natural resources (Mueller et al., 2004, Bock et al., 2005, and Gamanya et al., 2007). Object oriented image classification technique is a powerful and promising method of classification of high resolution satellite images by converting image pixels into objects utilizing both texture and contextual information. Kasper Johansen et al., 2009 showed the utility of high resolution data for delineation of banana plantations using a combination of object based classification and post classification visual editing.

With advancement in space technology, availability of high resolution data and advanced classifiers, remote sensing can provide a vital role in the inventory of horticultural crops. In this context, the present study was carried out to explore the potential use of high resolution data for identification and delineation of horticultural crop types using semi-automatic classification method vis-a-vis conventional visual interpretation techniques.

* Corresponding author 


\subsection{MATERIALS AND METHODS}

\subsection{Study Area}

Various representative study sites have been identified for plantation types grown under different agro-climatic regions of India. The selected horticultural crops and location of study areas are given below.
a) Mango:
Malihabad taluka, Uttar Pradesh
b) Banana:
Guntur, Andhra Pradesh
c) Citrus:
Sivagiri taluk, Tamil Nadu
d) Coffee:
Belur taluk, Karnataka
e) Coconut:
Tiptur taluk, Karnataka

\subsection{Satellite Data}

High resolution LISS-IV (Resourcesat-1/2) data with $5.0 \mathrm{~m}$ spatial resolution and Cartosat-1 data with $2.5 \mathrm{~m}$ spatial resolution acquired during 2013-14 has been used for delineation of horticultural crops in the study. Additionally, multi-date LISS-III with spatial resolution of $24.0 \mathrm{~m}$ is used to study phenology to determine the temporal window of optimum high resolution data for improved discrimination. The characteristics and details of satellite datasets are described in Table-1. Digital Elevation Model (DEM) with $10 \mathrm{~m}$ contour interval was generated using Carto-1 stereo data and used for orthorectification of satellite datasets.

Table-1: Characteristics of satellite data

\begin{tabular}{|c|l|c|c|c|}
\hline SN & \multicolumn{1}{|c|}{ Details } & Carto-1 & LISS-III & LISS-IV \\
\hline \multirow{3}{*}{1} & & & $0.52-0.59$ & $0.52-0.59$ \\
& Spectral & $0.5-0.85$ & $0.62-0.68$ & $0.62-0.68$ \\
& Resolution $(\mu \mathrm{m})$ & & $0.77-0.86$ & $0.77-0.86$ \\
& & & $1.55-1.70$ & \\
\hline 2 & Resolution $(\mathrm{m})$ & 2.5 & 23.5 & 5.0 \\
\hline 3 & Swath $(\mathrm{km})$ & $29 / 26$ & 141 & $24 / 70$ \\
\hline 4 & Quantization & 10 & 7 & $7 / 10$ \\
\hline 5 & Repetivity (days) & 126 & 24 & 70 \\
\hline 6 & Revisit (days) & 5 & 24 & 5 \\
\hline 7 & Stereo & Fore /Aft & - & - \\
\hline
\end{tabular}

\subsection{Pre-processing of satellite data}

The pre-processing steps consisted of orthorectification, radiometric normalization, generation of NDVI and data fusion of multisource data. Orthorectification of the datasets was carried out using DEM in UTM projection and WGS 84 spheroid. Vegetation indices were generated from temporal LISS-IV data for subsequent use in classification. Optionally, data fusion of ortho-rectified LISS-IV data and Carto-1 data was carried out using standard data merging technique.

2.3.1 Orthorectification: The orthorectification is the process which removes the geometric distortion inherent in the satellite imagery caused by camera/sensor orientation, topographic relief displacement and systematic errors associated with imagery. Initially, each Cartosat-1 data along with RPCs (Rationale Polynomial Coefficients) was orthorectified using 8-10 uniformly distributed ground control points (GCPs) and DEM. These datasets were later mosaicked to prepare Cartosat-1 ortho database.
Cartosat-1 ortho database was used as reference for orthorectification of individual LISS-IV and LISS-III scenes using RPCs, 8-10 GCPs and DEM employing projective transformation.

2.3.2. Radiometric normalization: Radiometric normalization was carried out to minimize the error. A userfriendly semi-automatic software package developed in ERDAS was used for conversion of DN image to radiance as well TOA reflectance image. Initially the digital numbers were converted to radiance as per the equation (1).

$$
\begin{gathered}
\text { Radiance }=\left(\mathrm{DN} / \mathrm{DN}_{\max }\right)\left(\mathrm{L}_{\max }-\mathrm{L}_{\min }\right)+\mathrm{L}_{\min } \\
\mathrm{L}_{\min }=\text { Minimum radiance, } \mathrm{L}_{\max }=\text { Saturation radiance, } \\
\mathrm{DN}_{\max }=\text { Radiometric resolution }
\end{gathered}
$$

In the next step, the radiance was converted to Top of the Atmosphere (TOA) reflectance or apparent reflectance. The sun elevation angle is derived using header file. The date of pass of satellite data was used for calculation of Julian day. TOA reflectance images were generated using equation (2).

$$
\text { TOA }(\rho \lambda)=\left(\pi * L_{\lambda} * d^{2}\right) /\left(E_{o} * \cos (\Theta)\right)
$$

$\mathrm{L}_{\lambda}=$ Spectral Radiance $\left(\mathrm{mW} \mathrm{cm}{ }^{-2} \operatorname{ster}^{-1} \mu \mathrm{m}^{-1}\right)$

$\mathrm{d}^{2}=$ Sun distance in astronomical unit (AU)

$\Theta=$ Sun zenith angle in radians.

$\mathrm{E}_{\mathrm{o}}=$ Mean Solar Exoatmospheric irradiance $\left(\mathrm{mW} \mathrm{cm}^{-2} \mu \mathrm{m}^{-1}\right)$

2.3.3. NDVI generation: Radiometrically corrected LISS-IV and LISS-III data was used for generation of Normalized Difference Vegetation Index (NDVI). NDVI is a numerical indicator that uses the reflectance in red and near-infrared bands of the electromagnetic spectrum which is sensitive to vegetation cover, biomass, crop condition and density (Baruth et al, 2008). NDVI values range from -1 to +1 and is the most commonly used vegetation index for condition assessment and monitoring. It is also being widely used for crop classification using NDVI change as a consequence of crop growth. NDVI images have been generated for multispectral data using equation (3).

$$
\mathrm{NDVI}=\left(\mathrm{r}_{\text {nir }}-\mathrm{r}_{\text {red }}\right) /\left(\mathrm{r}_{\text {nir }}+\mathrm{r}_{\text {red }}\right)
$$

$r_{r e d}$ and $r_{n i r}$ indicate reflectance in red and near infrared bands

2.3.4 Data fusion: The data fusion technique is being routinely used for merging high resolution panchromatic data with coarse resolution multi-spectral data to generate high resolution multispectral data to improve both spectral and spatial resolution. The popular data fusion techniques include Brovey transform, Principal Component Analysis (PCA), Intensity Hue and Saturation (IHS) and wavelet methods. The Brovey technique integrates the imagery of different spatial resolutions using a ratio algorithm introduced by Bob Brovey (Earth Resources Mapping, 1990 and Abedini, 2000).

Data fusion of ortho-rectified LISS IV data of $5.0 \mathrm{~m}$ resolution and Cartosat-1 data of $2.5 \mathrm{~m}$ has been carried out using Brovey method. The resultant $2.5 \mathrm{~m}$ hybrid data is characterized by the multi-spectral information content of LISS-IV data and the spatial information of Cartosat-1 data. 


\subsection{Pre-field interpretation and ground truth}

In-season ground truth information is essential for analyses of satellite data for delineating fruit and plantation crops. Information on the spatial distribution of various LULC categories in general and plantation crops in particular, were collected during the field visits. Based on the variations of spectral signature as manifested on the satellite image, limited pre-field interpretation was carried out and representative sample sites were identified for collection of intensive ground information. Prints of satellite data with transport network was used for collection of ground truth.

Global Positioning System (GPS) was utilized for planning and guiding field visits for identifying accurate locations of sample sites. The hand held Garmin GPS instrument was connected to Laptop for online visualization and monitoring of GPS tracks and sample points on the ArcMap for identifying sample points on the ground. These GPS tracks, the field photos and details were stored in the laptop for generation of digital database on the sample sites for generation of digital library of ground truth information.

\subsection{Classification}

Semi-automatic feature extraction model has been used for delineation of plantation crops of the study area. Object oriented classification technique available using ERDAS Objective Imagine has been utilized for classification of horticultural crops using high resolution data (Figure-1). Resourcesat LISS-IV and Cartosat-1 PAN data along with the merged data has been used as source data for the feature extraction model.

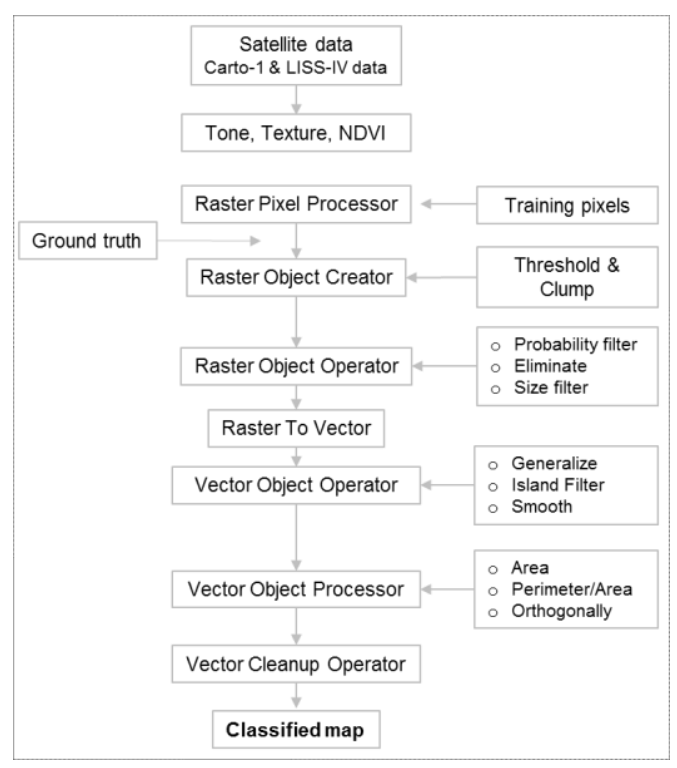

Figure-1: Steps involved classification technique

NDVI image from LISS-IV data, texture from Cartosat-1 data and spectral information from the merged data was used as input for generation of Spectral Feature Probability (SFP) layer. The definition of training areas for plantations as well as for background pixels is of central importance in the classification process. The SFP layer was converted into raster objects using threshold and clump function resulting in pixel probability layer. A set of raster and vector operators such as probability filter, eliminate, size filter and island filter was employed in the subsequent steps for generating the thematic map in vector format.

\subsection{Post classification editing and accuracy assessment}

The classified data was further refined using minimum onscreen visual interpretation at 1:10,000 scale for improving the accuracy using merged data. The final thematic maps were verified in the field for accuracy assessment in terms of mapping accuracy. A fraction of the interpreted polygons were randomly chosen for field checking. GPS based field verification was carried out for assessing the mapping accuracy (MA) calculated as per equation (4).

$$
\mathrm{MA}=\frac{\text { Correctly classified plygons }}{\text { Totoal No.of polygons }} X 100
$$

\subsection{RESULTS AND DISCUSSION}

\subsection{Mango}

Temporal LISS-IV data covering Malihabad test site was used to initially study the NDVI response of mango plantations for selection of optimum RS data for discrimination of mango plantations is depicted Figure-2.
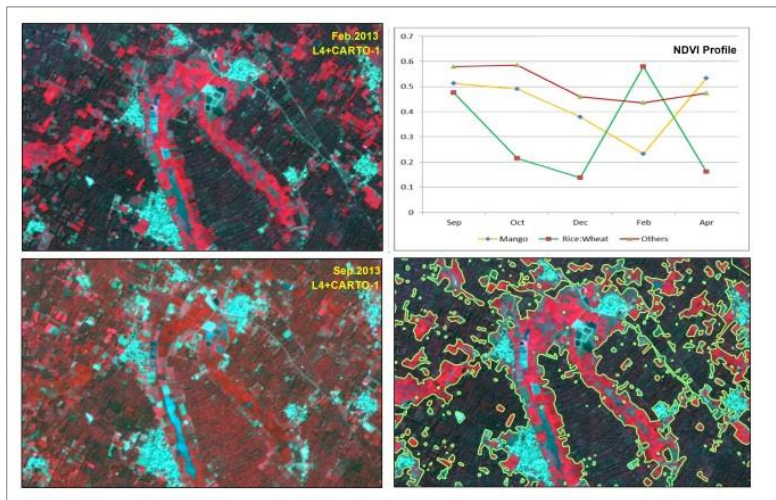

Figure-2: Delineation of mango plantations in Malihabad

The NDVI response of mango plantations was quite different from the agricultural crops of the study area. It was observed that February month data was more suitable for discrimination of mango plantations, primarily due to harvesting of competing agricultural crops. Accordingly, February 2013 data was used for classification of mango plantations using object based classification. Homogeneous and contiguous plantations could be delineated using high resolution data. However, techniques need to be developed for delineation of these plantations grown under diverse agro-horticultural systems with wide spacing between trees and very young orchards.

\subsection{Banana}

Guntur is well known for cultivation of banana orchards due to availability of water from the Krishna river. The study area is characterised by heterogeneous cropping pattern consisting of cotton, chillies, rice, citrus and tobacco. The classified map showing banana orchards is depicted in Figure-3. The banana crop manifested in bright red tone due to close spacing fully covering the soil background and lush green colour of the canopy. The spectral information alone aided in better classification for discrimination of banana orchards. However, the spectral signature of the crop often 
mixes with cotton and chillies in satellite data pertaining to October and November months. Thus, single date RS data was not sufficient for classification of banana orchards due to spectral confusion and two dates were critical for classification of banana orchards of the study area.
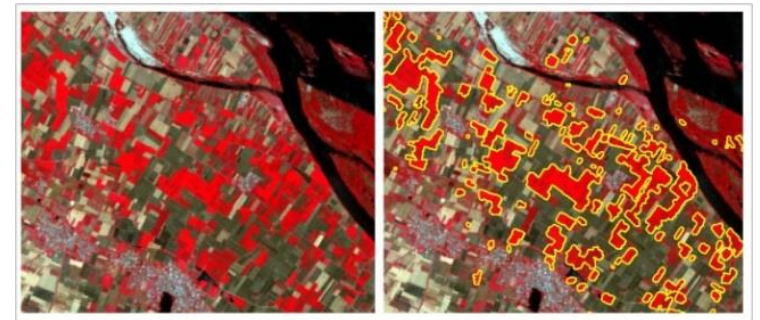

Figure-3: Distribution of banana plantations in Guntur, AP

\subsection{Citrus orchards}

Citrus orchards are extensively cultivated in Sivagiri taluq, Tamil Nadu and the fruits are predominantly exported. The soils and climatic conditions of the region are well suited for cultivation of acid lime. Although, four dates LISS-IV data was analysed, it was observed that only two date's data corresponding to October and March months were ideal for discrimination of citrus orchards for obtaining reasonable classification accuracy (Figure-4)

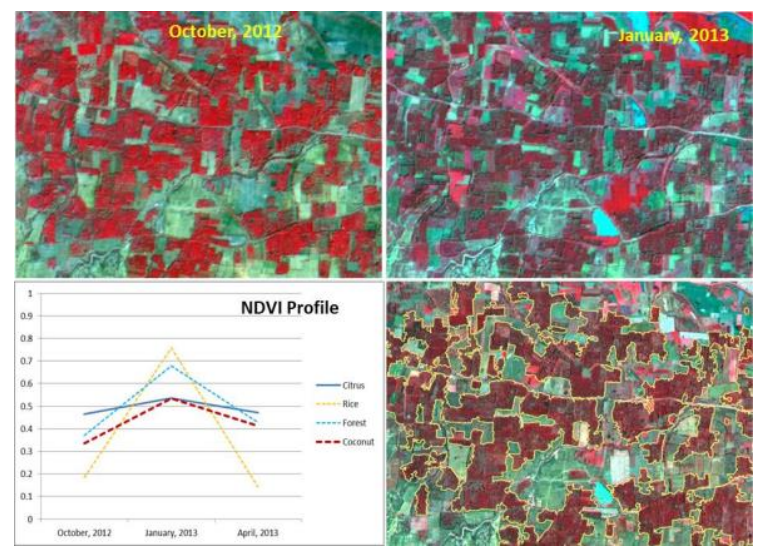

Figure-4: Inventory of citrus orchards using multi-date data

\subsection{Coffee}

Belur taluq is known for diversified horticultural plantations in Karnataka state. Coffee is the major commercial plantation crop in the western part of the taluq while coconut, arecanut, eucalyptus are the important plantation crops in the eastern region of the study area besides large tracts of forest land.
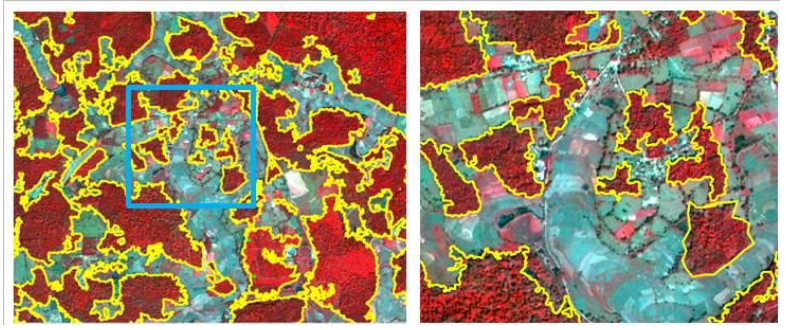

Figure-5: Inventory of Coffee plantations in Belur
The distribution of coffee plantations delineated using high resolution data employing semi-automated is depicted in Figure-5. It was observed that coffee plantations could be separated from other plantation crops mainly due to shape, texture and size. A comparison of on-screen interpretation with that of semi-automated procedure showed very good agreement. However, recently planted coffee plantations could not be classified and the same could be delineated to a large extent through visual interpretation.

\subsection{Coconut}

Coconut plantations are predominantly cultivated in Karnataka state. Coconut being evergreen tree, temporal NDVI variations was minimal. Figure-6 shows spatial distribution of coconut plantations in the study area that were delineated using two dates LISS-IV and Cartosat-1 data following semi-automatic feature extraction technique. The results clearly showed the utility of high resolution data for delineation of coconut plantations. It was observed that data coinciding with February - April months is ideally suited for discrimination of coconut plantations as agricultural crops would be harvested by this time. Mature plantations were classified more accurately while young and recently planted plantations showed poor classification accuracy due to mixed spectral signature and poor stand of plantations. However, it may be difficult to classify coconut plantations that are typically planted along the field bunds/boundaries.

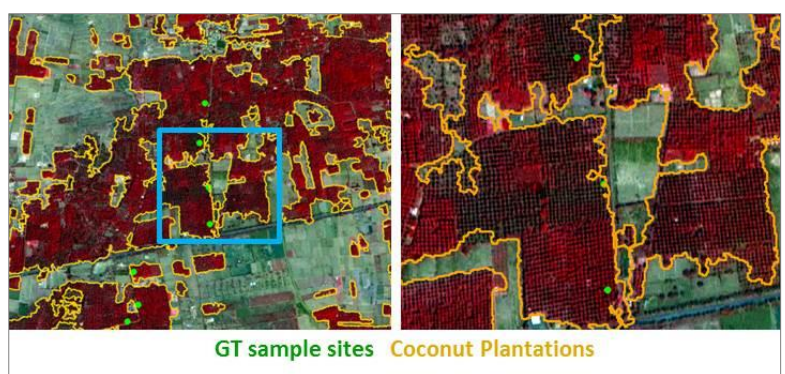

Figure-6: Delineation of coconut plantations in Tiptur,

\subsection{Classification Accuracy}

In the present study, only mapping accuracy was considered as single crop of interest was classified using the object based classification. Field verification of the classified data was carried out for post classification accuracy assessment in terms of mapping accuracy and depicted in Table-2. It was observed that mango and banana crops showed better classification accuracy of 89.2 and 91.4 per cent, respectively using object based classification alone. This could be attributed homogeneous crop stand and larger canopy covering the soils background. Marginal improvement in classification was achieved through post classification editing.

In contrast to this, citrus, coffee and coconut showed lower classification accuracy and post classification editing was necessary for improving the accuracy close to 90 per cent. The lower accuracy associated with object based classification could be due to heterogeneous cropping system, wider spacing and exposure of soil background resulting in mixed spectral signature. 
Table-2: Classification accuracy before and after editing

\begin{tabular}{|c|l|c|c|}
\hline \multirow{2}{*}{ S1 No } & \multirow{2}{*}{ Crops } & \multicolumn{2}{|c|}{ Mapping accuracy } \\
\cline { 3 - 4 } & & Object based & After Editing \\
\hline 1 & Mango & 89.2 & 93.5 \\
\hline 2 & Banana & 91.4 & 94.6 \\
\hline 3 & Citrus & 78.9 & 90.2 \\
\hline 4 & Coffee & 80.6 & 92.3 \\
\hline 5 & Coconut & 76.5 & 88.9 \\
\hline
\end{tabular}

\subsection{CONCLUSIONS}

The current study was carried out to explore the potential of high-resolution LISS-IV and Cartosat-1 data for mapping of horticultural plantations by semi-automated classification approach. Both textural and contextual information was used in the feature extraction model in addition to spectral and NDVI information for classification of plantation crops using object oriented technique. The classification technique was evaluated in five test sites under different agro climatic regions. The results were quite encouraging for delineation of major horticultural crops with reasonable classification accuracy of 75-80 per cent. Further improvement in accuracy could be achieved using minimal post classification visual editing especially for crops which were manifested in coarse texture on the satellite data. This study showed potential for semi-automation of classification process for delineation of horticultural crops.

The methodology is applicable for delineating homogeneous plantation patches and displays limited utility particularly for heterogeneous patches, small holdings and multi-cropped regions. Similarly, identification of younger plantations, discrimination of plantations under agro-horticultural systems and mixed cropping-system situations are some of the additional limitations. The current study is limited to smaller geographical area and further research is necessary for automation of the classification process at regional and state levels for operational application of high resolution data for horticultural crop inventory.

\subsection{REFERENCES}

Abedini, M., 2000, Satellite image fusion using Brovey. M.Sc Thesis, Geomatics Engineering, KN Toosi University of Technology, Iran.

B. Baruth, A. Royer, A. Klisch, G. Genovese, 2008, The use of remote sensing within the mars crop yield monitoring system of the European commission. The International Archives of the Photogrammetry, Remote Sensing and Spatial Information Sciences. Vol. XXXVII. Part B8. pp: 936-939.

Bock, M., P. Xofis, J. Mitchley, G. Rossner, and M. Wissen, 2005, Object-oriented methods for habitat mapping at multiple scales - Case studies from Northern Germany and Wye Downs, UK Journal for Nature Conservation, 13:7589.

Dadhwal V.K., Singh R.P., Dutta S. and Parihar, J.S., 2003, Remote sensing based crop discrimination and area estimation, A review of Indian Experience, Tropical Ecology, 43: 107-122.
Earth Resources Mapping Ltd., 1990, The Brovey transform explained. EMU forum. Vol. 2, No. 11 Available in www.ermapper.com/forum_new/emuf2-11

Gamanya, R., P.D. Maeyer, and M.D. Dapper, 2007. An automated satellite image classification design using objectoriented segmentation algorithms: A move towards standardization, Expert Systems with Applications, 32:616624.

Hebbar, K.R. and Krishna Rao, M.V. 2002, Potential of IKONOS data for horticultural crop inventory, Project report, NRSC, Hyderabad

IHD, 2013. Indian Horticulture Database (2013), National Horticulture Board, Min. of Agriculture, pp.289.

Kasper Johansen, Stuart Phinn, Christian Witte, Seonaid Philip, and Lisa Newton, 2009, Mapping Banana Plantations from Object-oriented Classification of SPOT-5 Imagery. PE \& RS, Vol. 75, No. 9, pp. 1069-1081.

Mueller, M., K. Segl, and H. Kaufmann, 2004. Edge- and region-based segmentation technique for the extraction of large, man-made objects in high-resolution satellite imagery, Pattern Recognition, 37:1619-1628.

Murthy, C.S., Sesha Sai, M.V.R., Bhanuja Kumari, V. and Roy, P.S., 2007, Agricultural drought assessment at disaggregated level using AWiFS /WiFS data of Indian Remote sensing satellites, Geocarto Int., 22, 127-140.

NHRDF, 2012, Annual Report, National Horticulture Research and Development Foundation, Nashik.pp.108.

RRSC-South, 2012, Geospatial technique for inventory of rubber plantations and identification of potential waste lands in Tripura state. Project report. RRSC/NRSC, www.nrsc.gov.in/pdf/prubber.pdf.

Srivastava, R.J., and J.L. Gebelein, 2007. Land cover classification and economic assessment of citrus groves using remote sensing, ISPRS Journal of Photogrammetry and Remote Sensing, 61:341-353.

Tenkabail P.S., Rao B.M., Pal P.K., and Das H.P., 2004, The use of remote sensing data for agricultural drought assessment and monitoring in Southwest Asia, International Water Management Institute (IWMI) Research report No. 85, Srilanka.

Yadav, I.S., N.K. Srinivasa Rao, B.M.C. Reddy, R.D. Rawal, V.R. Srinivasan, N.T. Sujatha, C. Bhattacharya, P.P. Nageswara Rao, K.S. Ramesh, and S. Elango, 2002. Acreage and production, estimation of mango orchards using Indian Remote Sensing (IRS) satellite data, Scientia Horticulturae, 93:105-123. 